\title{
Modelling the cohesive sediment transport in the marine environment: the case of Thermaikos Gulf
}

\author{
Y. N. Krestenitis ${ }^{1}$, K. D. Kombiadou ${ }^{1}$, and Y. G. Savvidis ${ }^{2}$ \\ ${ }^{1}$ Laboratory of Maritime Engineering and Maritime Works, Division of Hydraulics and Environmental Engineering, \\ Department of Civil Engineering, Aristotle University of Thessaloniki, 541 24, Thessaloniki, Greece \\ ${ }^{2}$ Department of Fisheries \& Aquaculture Technology, Alexander Technological Educational Institute of Thessaloniki, 632 00, \\ Nea Moudania, Halkidiki, Greece
}

Received: 18 April 2006 - Published in Ocean Sci. Discuss.: 5 July 2006

Revised: 16 October 2006 - Accepted: 5 February 2007 - Published: 13 February 2007

\begin{abstract}
The transport of fine-grained sediments in the marine environment entails risks of pollutant intrusions from substances absorbed onto the cohesive flocks' surface, gradually released to the aquatic field. These substances include nutrients such as nitrate, phosphate and silicate compounds from drainage from fertilization of adjacent cultivated areas that enter the coastal areas through rivers and streams, or trace metals as remainders from urban and industrial activities. As a consequence, knowledge on the motion and distribution of sediment particles coming from a given pollutant source is expected to provide the 'bulk' information on pollutant distribution, necessary for determining the region of influence of the source and to estimate probable trophic levels of the seawater and potential environmental risks. In that aim a numerical model has been developed to predict the fate of the sediments introduced to the marine environment from different pollution sources, such as river outflows, erosion of the seabed, aeolian transported material and drainage systems.
\end{abstract}

The proposed three-dimensional mathematical model is based on the particle tracking method, according to which matter concentration is expressed by particles, each representing a particular amount of sedimentary mass, passively advected and dispersed by the currents. The processes affecting characteristics and propagation of sedimentary material in the marine environment, incorporated in the parameterization, apart from advection and dispersion, include cohesive sediment and near-bed processes. The movement of the particles along with variations in sedimentary characteristics and state, carried by each particle as personal information, are traced with time. Specifically, concerning transport processes, the local seawater velocity and the particle's settling control advection, whereas the random Brownian motion due to turbulence simulates turbulent diffusion. The

Correspondence to: K. D. Kombiadou

(kobiadou@civil.auth.gr) vertical stratification of the water-column is taken into consideration by appropriate damping of the vertical diffusion term. Variations in cohesive sediment properties during the abidance in the aquatic environment include coagulation and flock break-up processes, quantification of the effects of ambient density to the density of the cohesive aggregate and the associated alterations to the falling speed of the particle. In the vicinity of the seabed, particles may deposit and gradually consolidate with time, the particles remain settled onto the bed, re-enter the flow at a later temporal point or may enter the water column for the first time, originating from the erosion of the bed. The occurrence of each of the aforementioned near-bed processes is defined according to the prevailing benthic shear stress conditions.

The mathematical model has been applied to the Thermaikos Gulf, an area of high environmental and socioeconomic importance but also a region of significant pollutant forcing from various anthropogenic activities taking place in the adjoining land. Various kinds of outputs can be extracted, such as trajectories of the overall movement of specific particles and related alterations of their characteristics with time, snapshots of the domain with respect to suspended or deposited matter and natural concentrations of sediments at every required temporal and spatial point. Indicative results from yearly and monthly simulations, using input baroclinic circulation data from the North Aegean Sea model and river discharges are presented and discussed, including outputs from a Typical One-Year Simulation (TOYS), the simulation of the period from 3 September 2001 to 31 August 2002 (S1A2) and the January 2003 experiment (J03).

The description of the processes that have been incorporated in the parameterization covers the most significant factors controlling transport and mixing of fine grained sediments in the marine environment, thus validating the accuracy and completeness of the model. One of the major advantages, apart from the observation of the phenomena in scales smaller than the grid size, describing the natural processes

Published by Copernicus GmbH on behalf of the European Geosciences Union. 
more accurately, is the flexibility in accepting various pollutant sources and the applicability to different domains with minor modifications. The model has been incorporated in the MFSTEP project, as part of the developed operational forecasting system for the Mediterranean Sea. The application can be used for the prognosis of the seawater quality for current and for future conditions, enabling employment as part of a near-real time observation system or to formulate decisions for the protection of the seawater environment.

\section{Introduction}

Freshwater input is, in general, a major provider of nutrients and heavy metals in coastal systems. Four rivers together with a complex system of irrigation channels contribute to the transport of water, nutrient pollutants and sediments from the adjacent land area to the Thermaikos gulf (location and morphology of the Gulf are discussed in Sect. 3). Elevated concentrations of nutrients and trace metals have been recorded in the riverine water of the gulf (Karamanos et al., 2000) due to utilization of the water for irrigation, urban and industrial purposes. Investigation of riverine plumes propagation in Thermaikos can lead to estimation of potential impacts of anthropogenic activities to the coastal system. Under this reasoning a three-dimensional sediment transport model was developed, describing mathematically the processes affecting the movement of fine particulate matter, which are highly associated with biochemical substances absorbed onto the flocks surface (Wang and Pinardi, 2002). Thus information on the motion of riverine cohesive sediments can result in prognosis of pollutant distribution in the aquatic domain.

Mathematical models describing the transport and dispersion of sediments in the coastal environment that have been developed and applied are Eulerian (e.g. Estournel, 2000), solving the well-known three-dimensional differential equations of transport and diffusion of matter concentration, particle tracking methods (e.g. Savvidis et al., 2001; Kourafalou et al., 2004), where advection and diffusion of a specific amount of mass is trailed with time, or combined EulerianLagrangian methods (e.g. Barros and Baptista, 1990), in which advection is expressed by particles whereas the dispersion is defined applying the finite differences scheme.

Selection of the particle tracking method for the simulation of the transport of the sediments in the marine environment was made due to major advantages of this approach over models with more "classical" methods. The random walk simulation model enables the observation of the phenomena in scales much smaller than the grid size, as well as the tracing of the movement of individual particles, thereby describing the natural processes more accurately. Concentrations of particles are easily calculated from the spatial positions of the particles and, more importantly, when and where required. Furthermore, errors due to numerical diffu- sion observed in methods such as finite differences or finite elements, are avoided and there is considerable reduction in computational time since the calculating load is restricted to the domain parts where the majority of the parcels are gathered.

In a random walk model the displacement of an arbitrary particle, at each time step consists of an advective, deterministic component and an independent, stochastic component. In a simplified one-dimensional transport model the Brownian motion of a particle can be described by a Langevin equation (Rodean, 1996):

$\frac{d x}{d t}=a(x, t)+b(x, t) \xi(t)$

where $\alpha$ and $b$ are the deterministic and stochastic parts respectively and $\xi$ is a random number. The equation of onedimensional diffusion of a conservative substance is:

$\frac{\partial C}{\partial t}=D \frac{\partial^{2} C}{\partial x^{2}}$

Solution of Eq. (2) for initial concentration $C_{o}$ is:

$C(x, t)=\frac{C_{o}}{\sqrt{4 \pi D t}} \exp \left(\frac{-x^{2}}{4 D t}\right), x \in(-\infty,+\infty), t>0$

The initial condition for the equation is $C_{o}=C(x, 0)=M \cdot \delta(x)$, where $M$ is the mass introduced to the flow at time $t=0$ and $\delta(x)$ is the Dirac delta function (Ganoulis, 1994). Posing $\sigma^{2}=2 D t$ the concentration is described by a Gaussian distribution with a mean value $\mu=0$ and variance $\sigma^{2}$. Considering that a particle oscillates randomly from point $x=0$ with amplitude of $\pm \Delta x$ and a probability function $p(x)$, varying uniformly between the maximal displacements, it follows that:

$$
\begin{aligned}
& p(x)=1 / 2 \Delta x, x \in(-\Delta x,+\Delta x) \\
& \mu=\int_{-\Delta x}^{+\Delta x} x p(x)=0 \\
& \sigma^{2}=\int_{-\Delta x}^{+\Delta x} x^{2} p(x)=\frac{\Delta x^{2}}{3}
\end{aligned}
$$

Thus, by the aforementioned equations it can be deduced that that the amplitude of the random Brownian particle motion $\Delta x$ is:

$\Delta x= \pm \sqrt{6 D t}$

\section{The three-dimensional model}

The formulated Lagrangian-based model describes the processes of sediment mass advection and dispersion processes along with aggregation, settling, deposition, erosion and consolidation of the cohesive particles. A large number of particles representing a particular amount of mass are introduced to the flow domain through a source, or sources. Their transport and fate is traced with time, as they are advected, dispersed and alter their properties due to physical phenomena affecting cohesive sediments in the marine environment. 
The movement of a particle is controlled by the local fluid velocity, the particle settling velocity and turbulent diffusion. Applying the aforementioned random walk parameterisation (Eqs. 1 to 5), the position for the ith particle introduced to the flow, in each time step, can be calculated by the equation:

$\frac{d x_{i}}{d t}=\left\langle u_{i}\right\rangle+u_{i}^{\prime}, \frac{d y_{i}}{d t}=\left\langle v_{i}\right\rangle+v_{i}^{\prime}, \frac{d z_{i}}{d t}=\left\langle w_{i}\right\rangle+w_{s, i}+w_{i}^{\prime}$

In the above set of equations $\left\langle u_{i}\right\rangle,\left\langle v_{i}\right\rangle$ and $\left\langle w_{i}\right\rangle$ are the velocities of the particle in $\mathrm{x}, \mathrm{y}$ and $\mathrm{z}$ directions respectively, defined by interpolation of the local ambient velocity components and $w_{s, i}$ the settling velocity of the ith particle, and account for the deterministic displacement. The fluctuating components $u_{i}^{\prime}, v_{i}^{\prime}$ and $w_{i}^{\prime}$ in Eq. (6) are the stochastic velocities that describe the Brownian motion of the particles calculated as:

$u_{i}^{\prime}=v_{i}^{\prime}=\sqrt{\frac{6 \cdot K_{H}}{d t}} \cdot \operatorname{rnd}[-1,1]$,

$w_{i}^{\prime}=\sqrt{\frac{6 \cdot K_{V}}{d t}} \cdot \operatorname{rnd}[-1,1]$

where $r n d[-1,1]$ is a random number distributed between -1 and +1 and $K_{H}$ and $K_{V}$ are the horizontal and vertical diffusion coefficients respectively. The horizontal diffusion coefficient is determined by Smagorinski formula (Mellor, 1996), in which $c$ is a parameter ranging, proportionally to the discretization step, from 0.01 to 0.2 :

$K_{H}=c \cdot d x \cdot d y \sqrt{\left(\frac{\partial u_{i}}{\partial x}\right)^{2}+\frac{1}{2}\left(\frac{\partial v_{i}}{\partial x}+\frac{\partial u_{i}}{\partial y}\right)^{2}+\left(\frac{\partial v_{i}}{\partial y}\right)^{2}}$

The value for the vertical diffusion coefficient is deduced from the horizontal, in relation to the proportionality between vertical and horizontal discretization (O' Brien, 1985), taking into account the effects of buoyancy and vertical stratification of the water column (Rodi, 1993):

$K_{V}=\frac{d z^{2}}{(d x \cdot d y)} \cdot K_{H} \cdot(1+3.33 \cdot R i)^{-1.5}$

$R i$ in Eq. (9) is the gradient Richardson number:

$R i=-\frac{g}{\rho_{w}} \cdot \frac{\frac{\partial \rho_{w}}{\partial z}}{\left(\frac{\partial U}{\partial z}\right)^{2}}$

In the above equation, $g$ is the gravity acceleration, $U$ the horizontal velocity and $\rho_{w}$ the seawater density. The simplified Lagrangean flocculation model (Winterwerp, 1998, 1999) has been employed for the determination of particle characteristic diameter $D_{a g}$, assuming small volumetric sediment concentration and fractal dimension $n_{f}$ equal to the average value for mud flocks $\left(n_{f}=2\right)$ :

$\frac{d D_{a g}}{d t}=k_{A} \cdot C \cdot G \cdot D_{a g}^{2}-k_{B} \cdot G^{3 / 2} \cdot D_{a g}^{2} \cdot\left(D_{a g}-D_{p}\right)$
The first term of the right hand side in Eq. (11) expresses the aggregate growth, while the second one the diameter reduction. In the previously cited equation, $G$ is the energy dissipation parameter, $C$ the suspended sediment concentration by mass and $D_{p}$ the diameter of the primary particles. It is noted that the initial particles bearing the characteristics as first introduced to the flow are considered as primary. The dimensional aggregation and flock breakup parameters, denoted $k_{A}\left[\mathrm{~m}^{2} / \mathrm{kg}\right]$ and $k_{B}\left[\mathrm{~s}^{1 / 2} / \mathrm{m}^{2}\right]$ respectively, are defined as:

$k_{A}=\frac{0.75 e_{c} \pi e_{d}}{f_{s} \rho_{s} D_{p}}, \quad k_{B}=\frac{0.5 \alpha e_{b}}{D_{p}}\left(\frac{\mu}{F_{y}}\right)^{\frac{1}{2}}$

in which, $e_{c}$ and $e_{d}$ are efficiency coefficients for coagulation and diffusion respectively, $f_{s}$ a shape factor (for spherical particles $f_{s}$ is around $\left.\pi / 6\right), \rho_{s}$ the density of primary particles, $a e_{b}$ the flock breakup efficiency parameter, $\mu$ the dynamic viscosity and $F_{y}$ the yield strength of the flocks.

The evolution of the density of the flock is calculated in relation to the porosity of the cohesive aggregate $(e)$, density of the solid phase $\left(\rho_{o}\right)$ and that of the seawater:

$\rho_{a g}=(1-e) \cdot \rho_{o}+e \cdot \rho_{w}$

The sediment settling velocity is then computed using Stoke's law for cohesive flocks (Burd and Jackson, 1997):

$w_{s}=\frac{\left(\rho_{a g}-\rho_{w}\right) g}{\rho_{w} \cdot 18 v} D_{a g}^{2}$

A modified law-of-the-wall has been employed for the estimation of the shear stress velocity, taking into consideration potential density gradients at the bed. The velocity gradient is calculated by the velocity profile and not by the log-law approximation using damping function $F_{t}$ (Toorman et al., 2000):

$u_{*}=F_{t} \kappa z \frac{\partial U}{\partial z}$, and $F_{t}=(1+100 R i)^{-\frac{1}{3}}$

where $U$ is the horizontal velocity, $\kappa$ the Von Karman constant and $R i$ the Richardson number. The corresponding velocity gradient at the marginal grid of the bed $(\mathrm{km})$ is calculated as (Krestenitis, 1987):

$$
\left(\frac{\partial U}{\partial z}\right)_{k m}=\frac{3 U_{k m}-4 U_{k m-1}+U_{k m-2}}{2 d z}
$$

The bottom shear stress $\left(\tau_{b}\right)$, defined by the shear stress velocity $u_{*}$ as $\tau_{b}=\rho_{w} u_{*}^{2}$, is compared to the critical values of the shear stress for particle deposition, resuspension or entrainment of eroded particles from the seabed. Thus, a particle reaching the bed can deposit provided the shear stress is less than the critical shear stress for sediment deposition $\tau_{c r, d e p}$, calculated by the corresponding critical shear velocity with reference to the settling velocity of the particle 


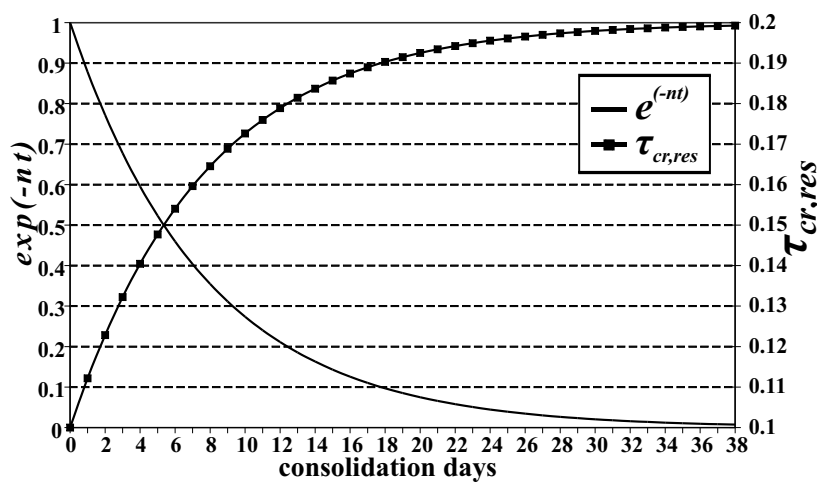

Fig. 1. Evolution of the exponential term in Eq. (20) (left axis) and the critical shear stress for resuspension of deposited sediments (right axis) with depositional time.

(Pohlmann and Puls, 1994):

$$
\begin{aligned}
& u_{\text {cr,dep* }}= \\
& \left\{\begin{array}{l}
0.008 \text { for } w_{s} \leq 5 \cdot 10^{-5} \mathrm{~m} / \mathrm{s} \\
0.008+0.02 \cdot\left(\log \left(w_{s}\right)+4.3\right) \text { for } 5 \cdot 10^{-5}<w_{s} \leq 5 \cdot 10^{-4} \mathrm{~m} / \mathrm{s} \\
0.028 \text { for } w_{s}>5 \cdot 10^{-4} \mathrm{~m} / \mathrm{s}
\end{array}\right.
\end{aligned}
$$

Determination of the erosion rate is made by a first order approximation, assuming a uniform, fully consolidated bed (Mehta, 1993):

$\varepsilon=\varepsilon_{\mathrm{M}} \cdot \frac{\tau_{b}-\tau_{c r, e r}}{\tau_{c r, e r}}$

$\varepsilon_{M}$ in Eq. (18) is an erosion rate constant and $\tau_{c r, e r}$ is the critical shear stress for erosion of the seabed. In general, values of the critical shear stress threshold and the erosion rate constant vary significantly with values of $\varepsilon_{M}$ from $10^{-5}$ to $10^{-3} \mathrm{~kg} / \mathrm{m}^{2} \mathrm{~s}$ and $\tau_{c r, e r}$ from nearly zero for organic rich to $10 \mathrm{~Pa}$ for hard consolidated beds. Table A1 presents values of the aforementioned parameters experimentally determined for various cases.

The erosion rate $\varepsilon\left[\mathrm{kg} / \mathrm{m}^{2} \mathrm{~s}\right]$ is multiplied by the horizontal spacing, which is the area of the grid cell $\left(\mathrm{m}^{2}\right)$ and by the time step (s), thus providing the mass of eroded sediment $(\mathrm{kg})$. The total mass set to motion due to erosion at each grid cell is divided by the typical particle mass and the closest integer of the division gives the number of eroded particles at each cell. The injection point of these particles is calculated by an algorithm that distributes the particles evenly to the grid area. Specifically the grid cell is divided to a smaller grid the dimensions of which $\left(b_{1} \times b_{2}\right)$ are the integer of the square root of the number of the eroded particles $\left(b_{1}\right)$ and the integer of the division of the number of the eroded particles to $b_{1}\left(b_{2}\right)$. If $N_{P}$ is the number of the eroded particles, then:

$b_{1}=i n t\left(\sqrt{N_{P}}\right), b_{2}=i n t\left(\frac{N_{P}}{b_{1}}\right), N_{P 1}=b_{1} \times b_{2}$

Thus, from the total number of the eroded particles, $N_{P 1}$ particles are evenly distributed at the center points of the new nested grid and the remaining $N_{P}-N_{P 1}$, if any, are injected at the center of the grid cell.

Newly deposited sediments undergo self-weight consolidation during the period of abidance on the seabed. At a simplified approach, consolidation can be considered as a process during which the excess pore-water pressure is transferred to the effective pressure. Evolution of the void ratio, and consequently porosity, with effective pressure follows a logarithmic law. As the consolidation rate decreases with time, porosity $(e)$ can be described an exponential decrease function:

$e=e_{\min }+\left(e_{o}-e_{\min }\right) \cdot e^{-n \cdot t}$

where $e_{\min }$ is the minimum aggregate porosity, obtained after full consolidation, $e_{o}$ is the initial value at the time of deposition, $t$ is time the particle has been under consolidation and $n$ is a coefficient dependant on the time considered for full consolidation of the particles. Since porosity and critical shear stress for resuspension $\left(\tau_{c r, \text { res }}\right)$ vary inversely with each other and supposing that the properties of the seabed are uniform with depth, it can be assumed that resuspension threshold values evolve with depositional time, following an equation of the form:

$\tau_{c r, \text { res }}=\tau_{c r, \text { dep }}+\left(\tau_{c r, e r}-\tau_{c r, d e p}\right)\left(1-e^{-n \cdot t}\right)$

Accepting that the process is completed in a period of 38 days (Winterwerp, 1999) and that critical shear stress values for deposition and erosion are $0.1 \mathrm{~Pa}$ and $0.2 \mathrm{~Pa}$ respectively, porosity and critical stress for resuspension as defined in Eqs. (20) and (21), evolve with consolidation time as presented in Fig. 1 (for $n=1,5 \cdot 10^{-5} \mathrm{~s}^{-1}$ ).

The calculation process in the mathematical code includes an external time-dependant loop, for which all of the physical and hydrodynamic parameters are defined for the aquatic domain, and an internal particle-dependant loop, executed for the overall number of particles that are "active" in the considered temporal step. Specifically in the external step, all input data values (velocities, temperature and salinity) are updated and necessary parameters, such as seawater density and shear stress velocity are being calculated. Following, the code proceeds to the internal iterative process, in which 3-dimensional transport and alterations to sediment characteristics are being defined by the corresponding values of the previous time step. Particles that are in suspension, those that have deposited but not yet fully consolidated and sediments that are for the first time introduced to the flow from the rivers or the seabed are defined as "active" for the time interval. After the completion of the particle loop, the calculated parameters handled by the program as personal information of each particle, including position, characteristics and state (in suspension, deposited, fully consolidated), are treated as past-information in the next temporal loop. 


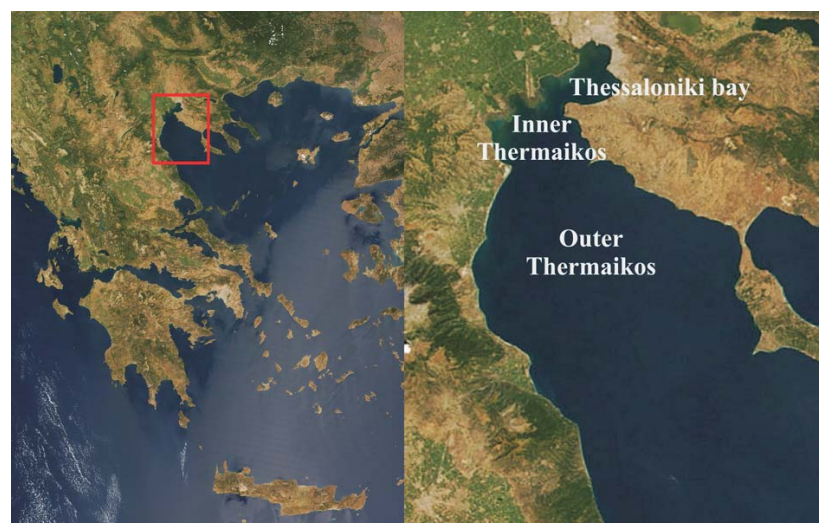

Fig. 2. Location of the computational domain in Greece (left panel) and enlargement of the area with notation of the parts comprising Thermaikos Gulf (right panel). The satellite image is the property of NASA.

\section{Description of the study area}

The model has been applied to the Thermaikos Gulf, situated in the north-western Aegean Sea (Eastern Mediterranean) (Fig. 2). Various socioeconomic activities take place in the vicinity of the gulf, forcing the marine system with agricultural, aquacultural and industrial residues. The city of Thessaloniki is a highly populated area located at the northern part, posing large amounts of biochemical pollutants and heavy metals and generally remains from urban, industrial and recreational uses to the environment. The presence of the intensely cultivated central Macedonia and Thessalia plains along the north and west coasts of the gulf entail that drainage from irrigation and fertilisation of the fields, and thus for organic-rich waters, find their way through a complex system of streams to the rivers of the area and finally to the sea. Two major rivers, Axios and Pinios along with two minor, Aliakmonas and Loudias affect the aquatic domain discharging fine sediments and nutrients.

Suspended sediments at the river mouths affecting Thermaikos have been characterised as very fine silt and clay (Karamanos and Polyzonis, 1998). Thus, in accordance to the grain size classification (McLane, 1995), the diameter of the primary particles is taken to be $3 \mu \mathrm{m}$, which is the mean value between very fine silt $(3.9 \mu \mathrm{m})$ and clay $(\sim 2 \mu \mathrm{m})$.

The bathymetry of the computational domain (Fig. 3), extracted from the North Aegean Sea model (Kourafalou et al., 2002), extends from the shallow parts of the northern Thermaikos to the deep southern parts of approximately $600 \mathrm{~m}$ where the gulf abuts the Sporades basin. The numerical grid applied is curvilinear in the horizontal direction with a step of $d x=d y=1 / 60^{\circ}$ and fixed vertical discretization of $d z=2 \mathrm{~m}$. Relatively small time step was selected for the simulations $(d t=720 \mathrm{~s})$, so as to avoid the possibility of a particle to overlap a grid at its movement in the time interval.

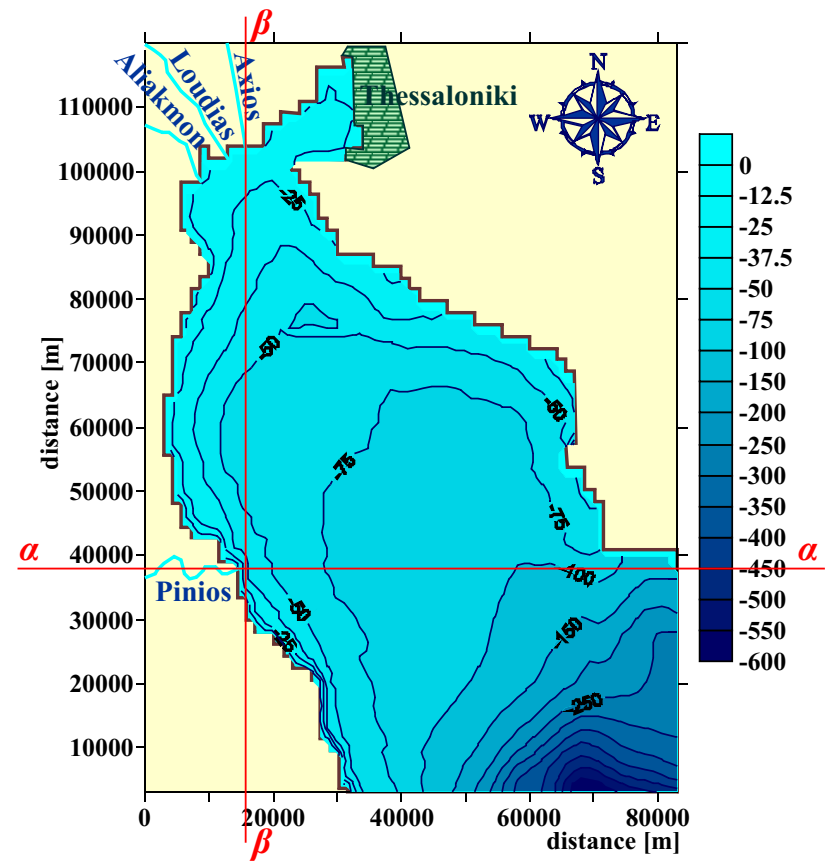

Fig. 3. Bathymetry of the computational domain with location of cross-sections $\alpha-\alpha$ and $\beta-\beta$.

The surface sediment layer of the sea bed in the gulf of Thermaikos mainly comprises of mixtures with generally low sand content that can be characterized as finegrained in the northern part and clayey in the deeper southern parts (Karageorgis and Anagnostou, 2001). Table A1 (Appendix A) contains values for the constants involved in the determination of eroded cohesive material (Eq. 18) from various laboratory or in situ experiments. It can be deduced that the mean value of the critical shear stress for erosion onset is of the order of $0.2 \mathrm{~Pa}$ for absence of a fluff layer and the corresponding erosion rate constant around $10^{-5} \mathrm{~kg} / \mathrm{m}^{2} \mathrm{~s}$. Due to lack of related research for the study area, these values have been considered appropriate for application, along with a critical shear for resuspension of newly deposited matter in Eq. (20) of the order of $0.1 \mathrm{~Pa}$.

Hydrodynamic and physical parameters of the aquatic environment are input for the mathematical code. These include seawater velocities, expressed at the sides of each grid shell along the horizontal and vertical directions, that are in fact the deterministic displacement, and temperature and salinity, expressed at the centre of the grid box, and determine seawater density by the equation of state. Their values are obtained by the Princeton Ocean Model (POM), implemented in the Northern Aegean Sea model, hereafter NAS (Kourafalou et al., 2002).

Each particle represents a particular amount of mass with the same sedimentary properties (aggregate characteristic diameter, density and porosity) that are being traced with simulation time as "personal information", which may however 


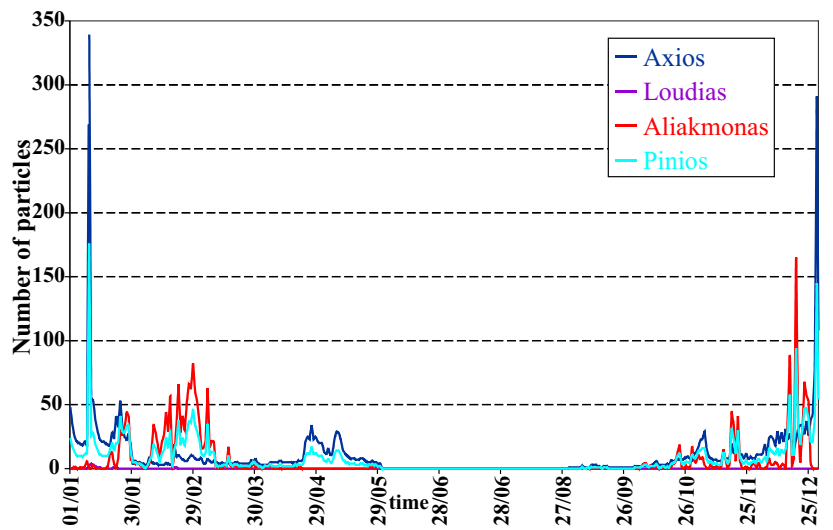

Fig. 4. Time-series of particle discharges in the gulf from the four rivers affecting the area.

be non-uniform between individual particles. The time series of the particles entering the gulf from the source-rivers for a typical annual simulation is given in Fig. 4 with the timeaxis' starting point at 1 January (Karamanos and Polyzonis, 1998). The particle mass was selected to be $4320 \mathrm{~kg}$.

\section{Results}

Outcomes from three implementations of the model are given for two yearly and one monthly simulation. They are the Typical One-Year Simulation (TOYS), the simulation of the period from 3 September 2001 to 31 August 2002 (S1A2) and finally the January 2003 experiment (J03) (Kourafalou and Tsiaras, 2007) concerning a run with half-daily mean input values (from the 3 to the 31 January at 00:00 and 12:00 UTC) and particle mass set to $1440 \mathrm{~kg}$. Input velocity and oceanographic parameters fields for TOYS are outputs of the NAS model with perpetual year forcing (Kourafallou and Barbopoulos, 2003; Korres and Lascaratos, 2003), describing seasonal circulation patterns. The hydrodynamic and physical parameters input data of the S1A2 run were obtained by implementation of POM with forcing from the POSEIDON forecasting System (Papadopoulos et al., 2002; Soukissian et al., 2002) of the Hellenic Centre for Marine Research.

Particle movement and associated alterations to the characteristic properties, as aforementioned, are being traced with time, allowing the visualisation of such results. Horizontal trajectories of randomly selected particles from the S1A2 run are presented in Fig. 5. In general, particles follow stochastic trajectories as they are being passively dispersed by the currents. A particle originating from Aliakmonas River (green line in Fig. 5) introduced to the flow at 24 November 2001 has crossed the gulf to escape to the open sea from the southern boundary of the domain at 6 December 2001, staying in suspension for 12 days. Correspondingly a particle discharged from Pinios estuary at 22 September

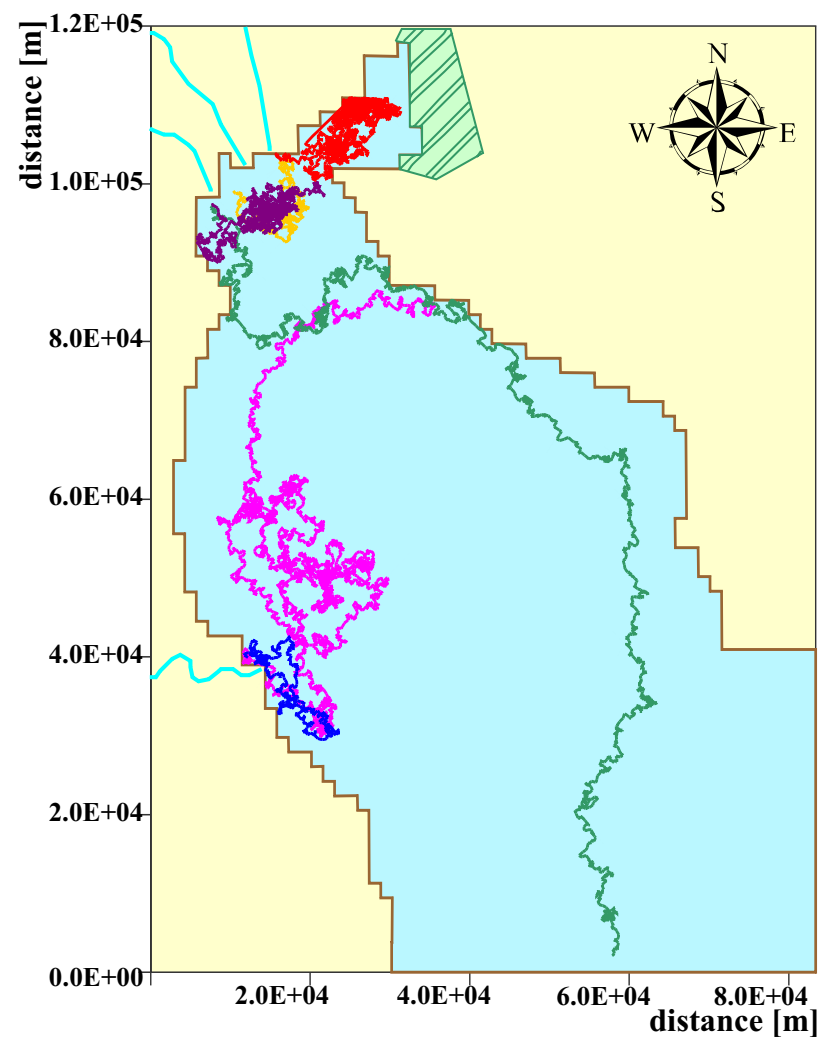

Fig. 5. Horizontal trajectories of randomly selected particles by the S1A2 simulation.

2001 (magenta line in Fig. 5) after performing an arbitrary movement for approximately 24 days, deposited on the shallow areas of the eastern coastline. The vertical propagation in the water column and the associated changes to sedimentary properties for the aforementioned particles are depicted in Figs. 6 and 7 respectively in which the horizontal propagation of each particle is given individually for clarity purposes.

Specifically Fig. 6 shows the vertical position of the particle discharged from Pinios (Fig. 6c) and the corresponding depth of the seabed in relation to the horizontal travelled distance (Fig. 6a) along with alterations to its characteristics with time (Fig. 6b). The only property that undergoes changes with time is the particle density, while characteristic diameter and settling velocity are stable throughout the movement of this particle. This can be attributed mainly to the shear stress of the flow that inhibited aggregate growth and forced characteristic diameter and settling rates to remain at low values. The density initially drops to increase again after a very short period. This coincides with the original southerly movement of the particle (Fig. 6c) during which dense waters enhanced the values of the aggregate density and forced the particle to an anticyclonic northerly movement (movement following $\mathrm{A}^{\prime}$ in Fig. 6c) in depths greater than $20 \mathrm{~m}$ (Fig. 6a). The settling rate remains constant, implying that seawater density and particle density fluctuate in 


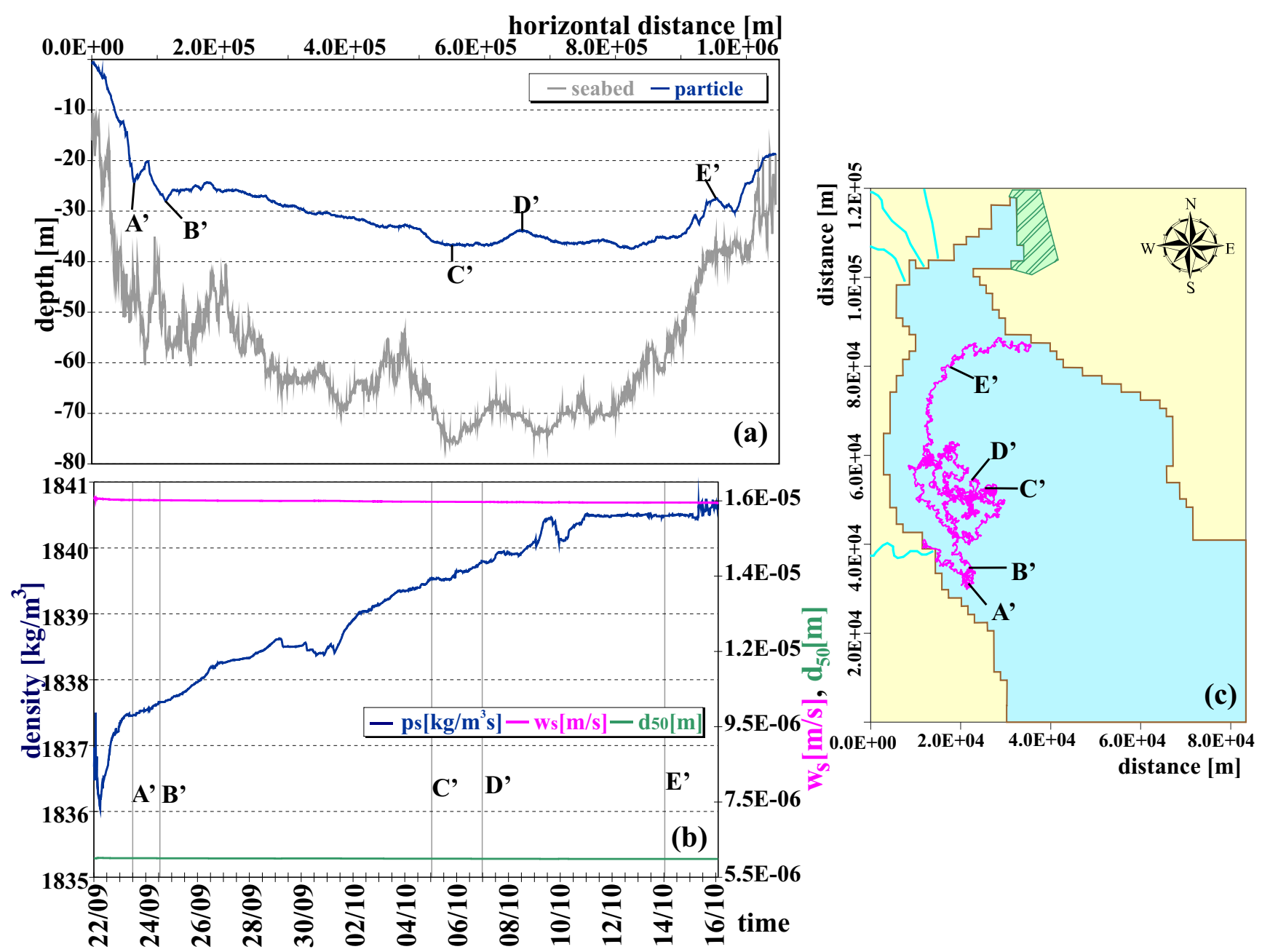

Fig. 6. Propagation and properties of the particle effluent from Pinios (magenta line in Fig. 5); (a) vertical pathway (blue line) and corresponding depth of the seabed (grey line) in relation to horizontal traveled distance; (b) variation of sediment characteristics with time (blue line indicates particle density, magenta line denotes settling velocity and green line represents sediment characteristic diameter); (c) horizontal trajectory of particle.

the same manner. By the characteristic points marked in the figure $\left(\mathrm{A}^{\prime}\right.$ to $\left.\mathrm{E}^{\prime}\right)$ it can be noted that since the settling velocity remains at a constant value throughout the movement, the vertical movement of the particle is controlled by the local vertical fluid velocity, namely by advection and diffusion processes.

Figure 7 presents the case of the particle from Aliakmonas that escaped the field to the Sporades basin. The particle stays in suspension at low depths for the greater part of the movement (Fig. 7a) despite the fact that coagulation proceeds rapidly causing related increase to the settling velocity (Fig. 7b). This is attributed to the local fluid velocity and stratification of the water column, which is corroborated by the abrupt deterioration of the density, entailing the presence of low density waters, which lasted for a period of 6 days from entrainment (point $\mathrm{A}^{\prime}$ ), after which density remained relatively stable. Specifically the shear of the flow forces the particle to initially surface (point $\mathrm{A}^{\prime}$ ) and shortly after relaxes and the particle starts to sink $\left(\mathrm{A}^{\prime}\right.$ to $\left.\mathrm{B}^{\prime}\right)$. After 28 November 2001 the local fluid velocities increase and cause the upward movement of the particle, with enhanced bottom shear stress that inhibited deposition of the particle at the eastern coast of the gulf (Fig. 7c). At point $\mathrm{C}^{\prime}$ the particle rises once more to remain at low depths for a period of 3 days (point $\mathrm{D}^{\prime}$ ) bearing stabilized particle characteristics (Fig. 7b) with maximal diameter and settling velocity and minimal density after which slowly moves to higher depths and finally exits the plateau towards Sporades basin.

Snapshots of the aquatic domain with respect to sediments can be extracted at every time step revealing variation in properties, origin and state. Figure 8 presents particles in the gulf that remain in suspension at the end of TOYS (Fig. 8a), 


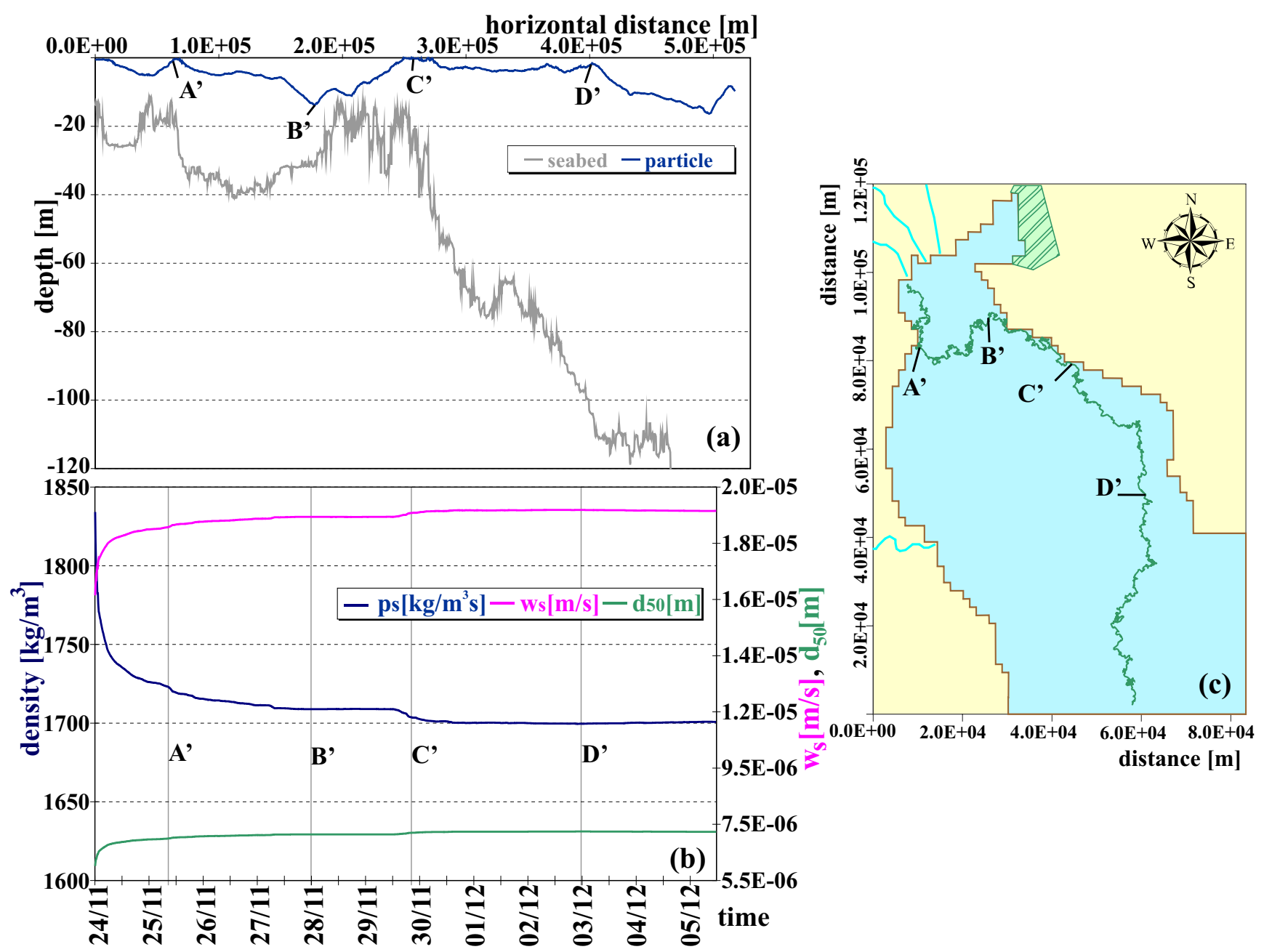

Fig. 7. Propagation and properties of the particle effluent from Aliakmonas (green line in Fig. 5); (a) vertical pathway (blue line) and corresponding depth of the seabed (grey line) in relation to horizontal traveled distance; (b) variation of sediment characteristics with time (blue line indicates particle density, magenta line denotes settling velocity and green line represents sediment characteristic diameter); (c) horizontal trajectory of particle.

S1A2 (Fig. 8b) and J03 (Fig. 8c) experiments. The chromatic encoding shown in the legend denotes the riverine origin of each sedimentary parcel. The high suspended masses from Axios River in Fig. 8a and c are due to the increased discharges recorded at the end of December and January (Fig. 4). In order to avoid visual misjudgment regarding the suspended masses in the gulf by inter-comparison of snapshots from the various experiments presented, it is noted that the particle mass for the J03 run was set to be at the $1 / 3$ of the equivalent for the TOYS and S1A2 runs. Correspondingly, the low amount of matter in Fig. $8 \mathrm{~b}$ is due to the lower summer outflows, since the results presented refer to $30 \mathrm{Au}-$ gust 2002. The contribution of sedimentary particles in summer is considered of special interest given that irrigation and related nutrient effluence, introduced from the drainage system, are enhanced during this period. The surface waters of the outer Thermaikos as simulated by the NAS model with perpetual year forcing (Kourafalou and Barbopoulos, 2003) form an anticyclonic eddy in the winter period. This clockwise movement of the surface waters at the west coast of the outer gulf (Kontoyiannis and Papadopoulos, 1998; Anagnostou et al., 1998) is apparent in the movement of the sedimentary particles, forcing particles to follow corresponding pathways in the outer Thermaikos (Fig. 8a). The inner gulf and the Thessaloniki bay are dominated by sediments originating from Axios and secondarily Loudias, due to the contiguity of the outflows to the inlet and to circulation that consists of southerly movement of surface waters combined with anti-cyclonic gyres in the deeper layers (Poulos et al., 2000). Generally the areas of the inner gulf and bay present high levels of sediment accumulation because of the proximity to the northerly river estuaries (Axios, Loudias and Aliakmonas) 


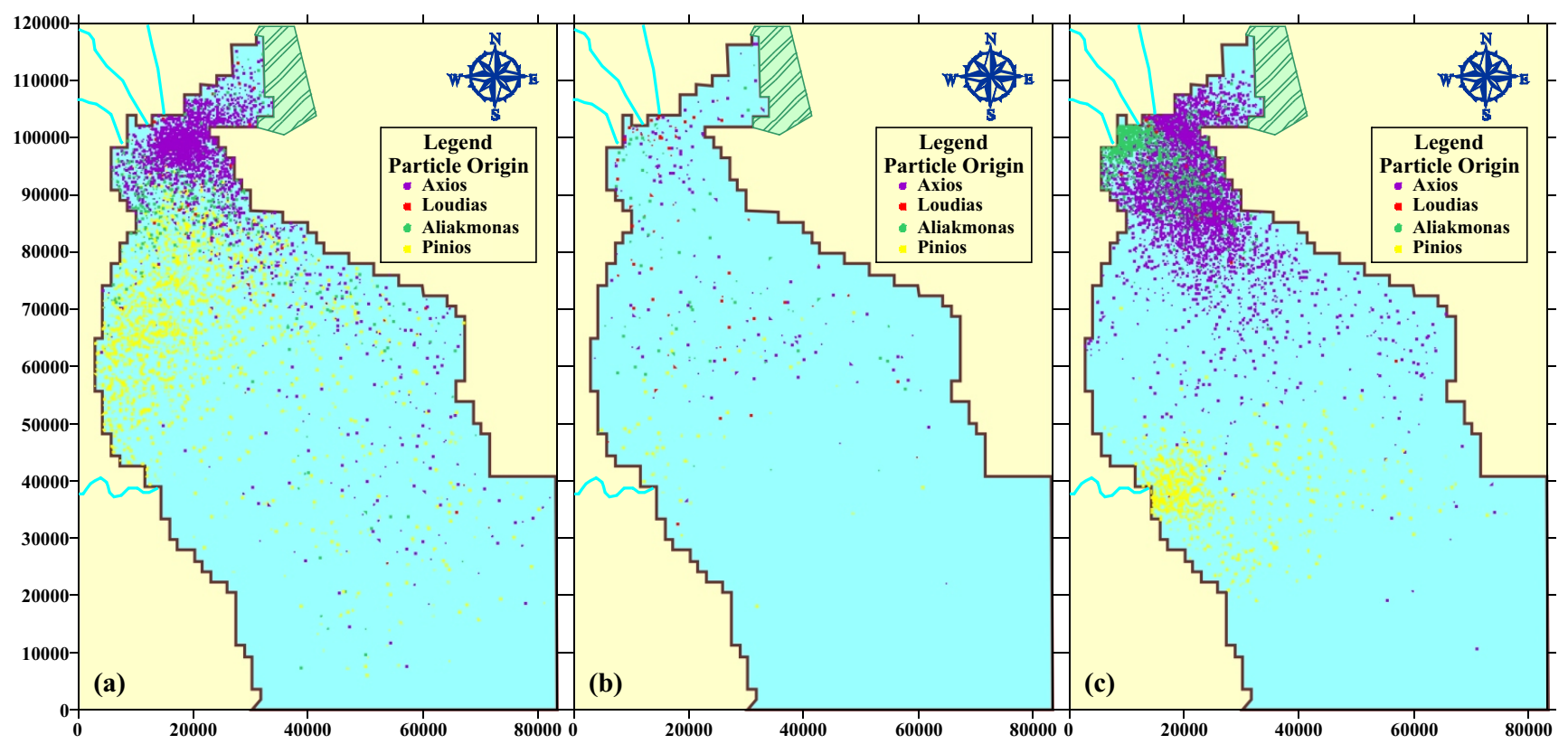

Fig. 8. Spatial variation of suspended sediments in the domain at the end of TOYS (a), S1A2 (b) and J03 (c) simulations (the horizontal and vertical axes specify the coordinate system of the domain $[\mathrm{m}])$.

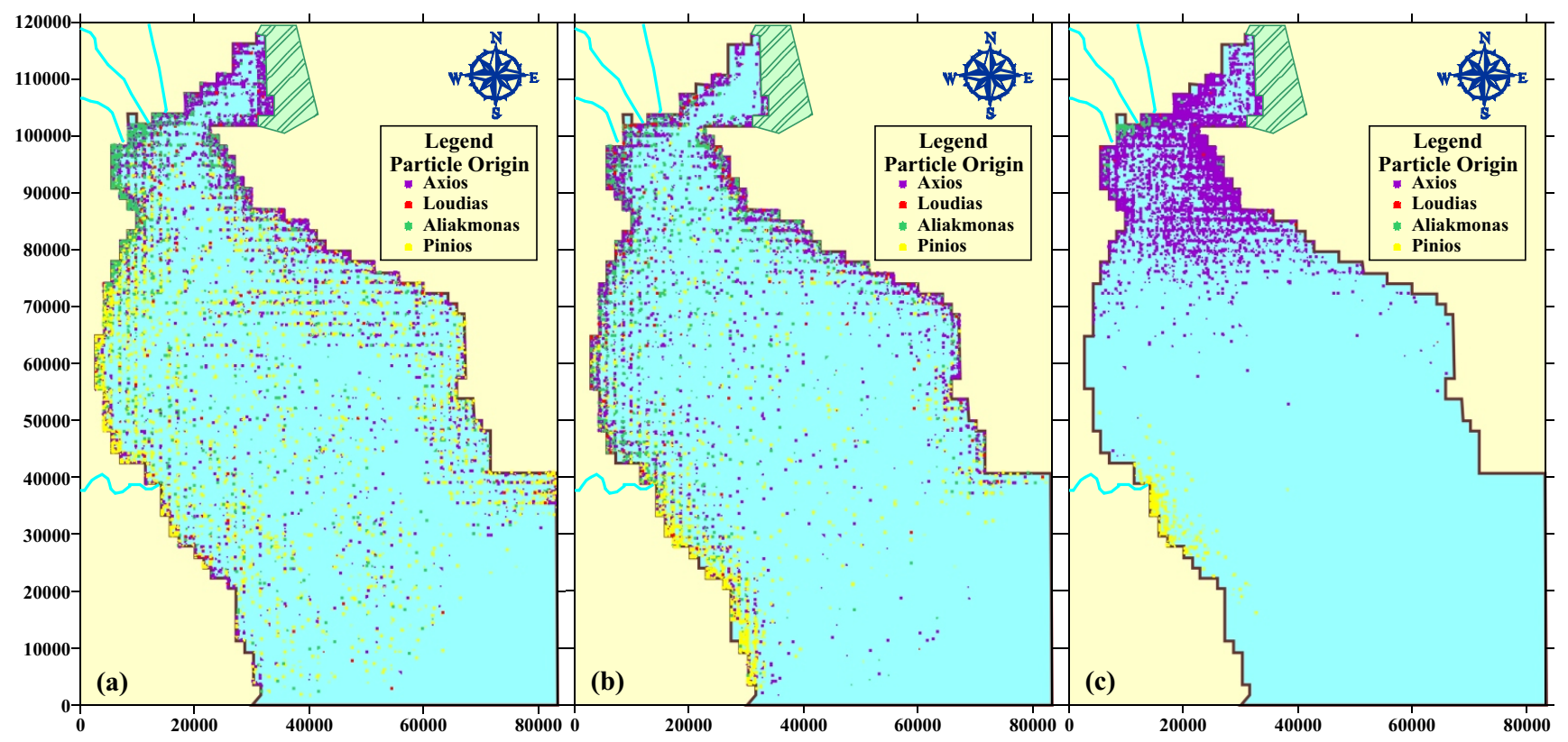

Fig. 9. Spatial variation of deposited sediments in the domain at the end of TOYS (a), S1A2 (b) and J03 (c) simulations. (the horizontal and vertical axes specify the coordinate system of the domain [m]).

and their lower depths. This is considered to be highly associated to the spring bloom of diatoms that appears in the gulf, usually in the period from February to May (Moustaka, 1997). Regarding the J03 run the northern riverine plume extends to the greater part of the inner gulf and the particles from Pinios spread at a significant distance from the west coast showing a southward tendency. This naturally is in accordance with the hydrodynamics of the simulation that reveal a southward buoyancy-driven coastal current that is strengthened by strong northerly winds during the last 5 days of the experiment (Kourafalou and Tsiaras, 2007).

Similar spatial variation of deposited sediments is presented in Fig. 9 enabling estimates for the sedimentation patterns existent in the Thermaikos. Matter from Aliakmonas 


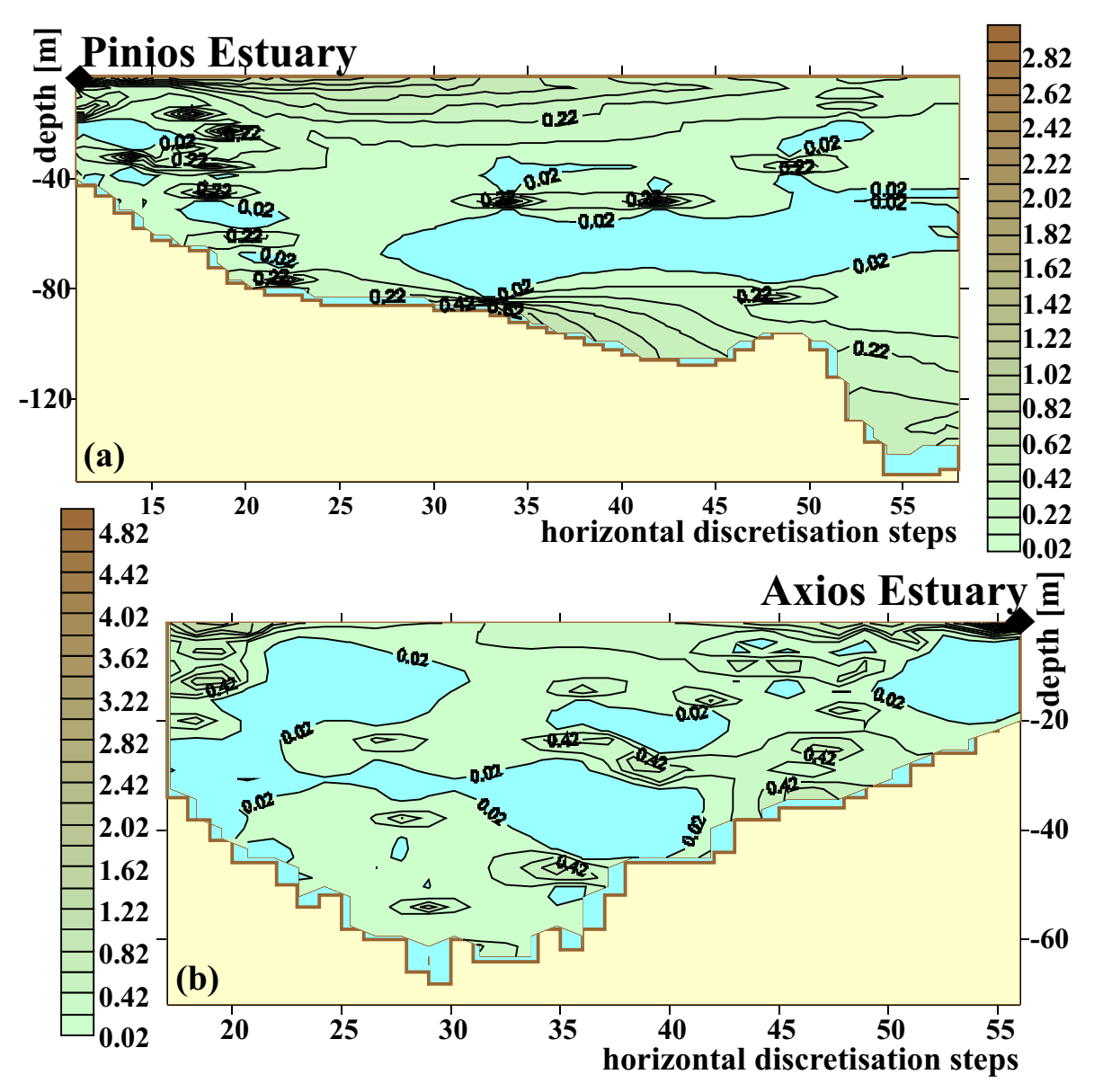

Fig. 10. Concentrations of suspended sediments, in $\mathrm{mg} / \mathrm{l}$, in cross-sections $\alpha-\alpha$ (a) and $\beta-\beta$ (b) for winter conditions from the $\mathrm{S} 1 \mathrm{~A} 2$ run. The vertical axis is the water depth $(\mathrm{m})$ and the horizontal denotes the horizontal position in number of discretization steps $\left(d x=d y=1 / 60^{\circ}\right)$.

mainly deposit along the western coast near the outflow, while Axios is the major sediment supplier for the Thessaloniki bay, along with small contribution from Loudias. Sediments from the system of the northernly rivers settle along the coastlines of inner Thermaikos with small input from Pinios and expand in smaller extent at the shallow parts of the outer gulf. Particles originating from Pinios settle at the shallow areas primarily of the western coastline and secondarily of the eastern. These observations are in accordance to the ones made by Lykousis et al. (1981). Pinios sedimentation pattern as revealed by TOYS (Fig. 9a) forms mainly to the north of the outflows. Circulation of the surface waters in the outer Thermaikos (Kourafalou and Barbopoulos, 2003), as simulated with perpetual year forcing, is anti-cyclonic in the winter and autumn seasons and turns cyclonic during spring and summer with southward freshwater flow along the western coast. Thus, Pinios plume in TOYS was confined by the anti-cyclonic gyre of the upper layer and stratification of the water column during the periods of high river-runoff, driving the particles to the north. Regarding the S1A2 period there are no published data from the NAS model. However during 2002 a pilot program to study the circulation in the
Aegean Sea using global positioning surface drifters was underway during which 30 drifters were launched in the northern Aegean (Olson et al., 2007), some of which reached and entered the Thermaikos gulf. The results have shown the presence of a coastal jet along the western side of the Aegean in 2002, which is in accordance with the tendency of particles from Pinios to move to the south of the gulf in the S1A2 experiment (Fig. 9b). At the end of J03 the bulk deposited particles from Pinios are located to the south of the estuary and mainly close to the coast. This movement is attributed to the aforementioned buoyancy driven current along the western coast that was enhanced after 25 January 2003 by strong northern winds (Kourafalou and Tsiaras, 2007) and enabled eastward spreading of the plume and sedimentation at greater depths along the west coast.

Concentrations of suspended matter can be calculated by the spatial distribution of particles and particle mass for every required temporal point. Figures 10 and 11 indicatively present the concentration of suspended sediments at crosssections $\alpha-\alpha$ and $\beta-\beta$ (see Fig. 3 for the location of the sections) in winter (8 January 2002) and early summer (22 May 2002) respectively, as estimated by the S1A2 run. Indexes 


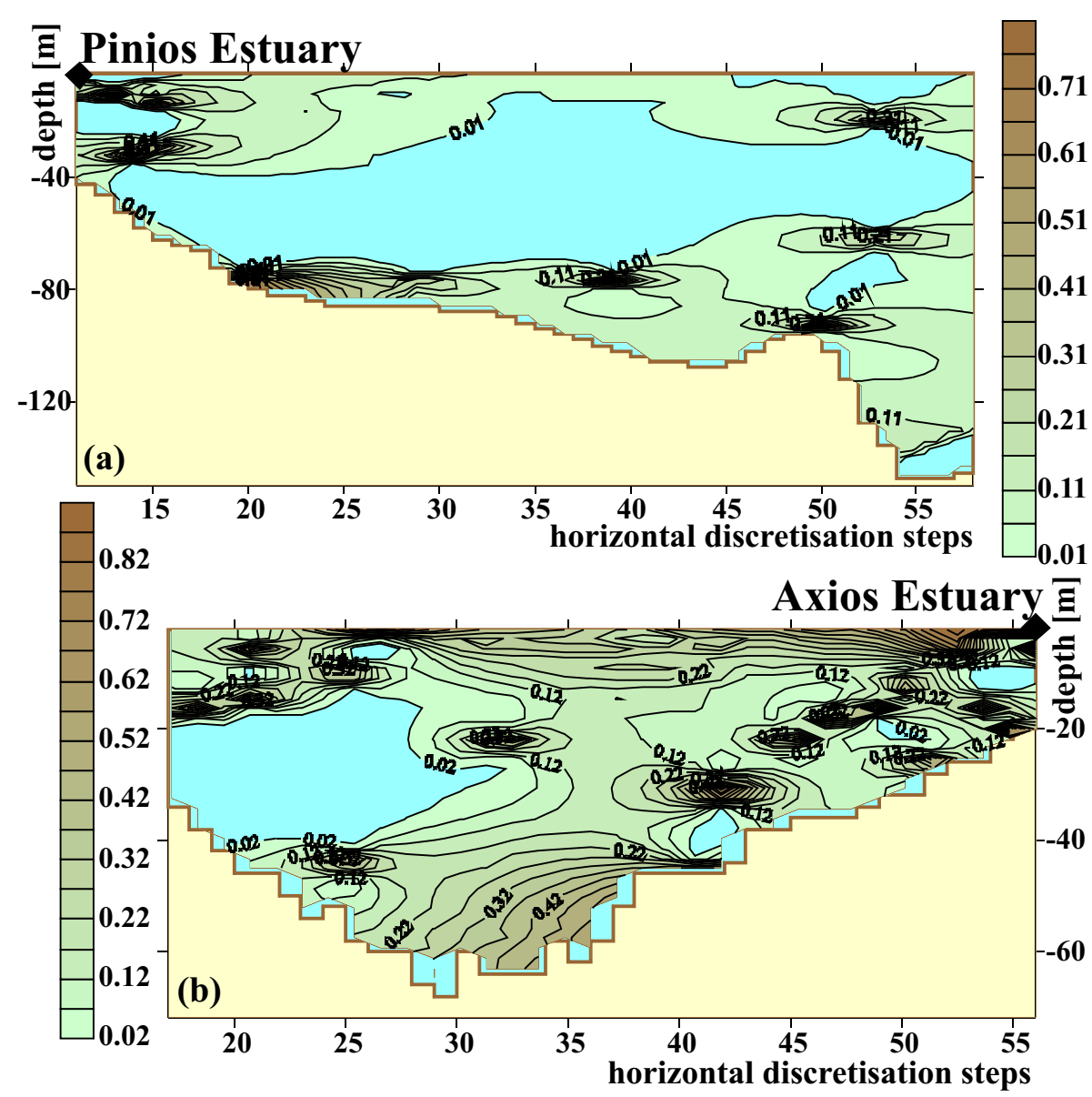

Fig. 11. Concentrations of suspended sediments, in $\mathrm{mg} / \mathrm{l}$, in cross-sections $\alpha-\alpha$ (a) and $\beta-\beta$ (b) for early summer conditions from the $\mathrm{S} 1 \mathrm{~A} 2$ run. The vertical axis is the water depth $(\mathrm{m})$ and the horizontal denotes the horizontal position in number of discretization steps $\left(d x=d y=1 / 60^{\circ}\right)$.

$\mathrm{a}$ and $\mathrm{b}$ in the figures in question denote sections $\alpha-\alpha$ and $\beta-\beta$ correspondingly. Maximum concentrations appear in the vicinity of the river outflows and the surface layers, due to stratification of the water-column by freshwater inflow. Surface nepheloid layers (SNL) and bottom nepheloid layers (BNL) are present in both seasons, as often reported in Thermaikos by various researchers (Poulos et al., 2000; Karageorgis and Anagnostou, 2001). Considering winter conditions for the Pinios estuary concentrations of the SNL are in the order 0.5 to $1 \mathrm{mg} / \mathrm{l}$ in the vicinity of the river mouth and for Axios the corresponding concentration is elevated ranging from 1 to locally $2 \mathrm{mg} / \mathrm{l}$. In general suspended matter appears significantly lessened in the summer (Fig. 11) due to decreased riverine discharges, with SNL concentrations varying from 0.5 to $1 \mathrm{mg} / \mathrm{l}$ very close to the deltas and mean concentration in the order of $0.05 \mathrm{mg} / \mathrm{l}$ for $\alpha-\alpha$ and $0.1 \mathrm{mg} / \mathrm{l}$ for $\beta-\beta$ cross-sections. Related BNL concentrations in the gulf, mainly caused by resuspension events (Karageorgis et al., 2000) are quite low, of the order of 0.2 to $0.5 \mathrm{mg} / \mathrm{l}$, whereas the mean suspended matter for the greater part of the gulf is in the order of 0.1 to $0.2 \mathrm{mg} / \mathrm{l}$. The BNL presents local maxima that reach corresponding concentrations of the winter values.

\section{Conclusions}

The three-dimensional sediment transport model presented is based on the particle tracking method describing the processes of advection and dispersion of particulate matter and the processes of flocculation-deflocculation, settling, deposition, resuspension and consolidation of cohesive sediment flocks. The model has been applied for the case of the Gulf of Thermaikos with four rivers as input sources of particulate matter. Indicative results from three different simulations were presented, including representations of horizontal and vertical particle trajectories along with the evolution of the characteristic properties of suspended particles with time. The model facilitates the visualisation of the spatial variation of particles with relation to personal information, the most interesting of which is the origin of the material, allowing 
investigation of patterns of sedimentary plume propagation existent in the coastal system. Concentrations of particulate matter can be deduced by particle mass and location and were presented for two cross-sections located at the estuaries of the two major rivers discharging in Thermaikos.

In general the movement of sediments in the Gulf, as expected, appears to be highly influenced by the seasonal circulation of the water masses. The inner gulf and bay are dominated by sediments originating from the northerly river system in terms of suspended and deposited masses with the contribution of Pinios to be at a small extent. The outer Thermaikos follows a general cyclonic pattern in both sedimentary plume propagation and sedimentation patterns. The presence of surface and bottom nepheloid layers, often reported occurrences in the gulf are reproduced by the model, as depicted in the results presented.

The parameterisation of the processes affecting the transport and mixing of sediments in the marine environment applied in the mathematical model is considered complete, covering the most important factors controlling the phenomena. The model is fully functional and able to accept various kinds of input pollutant sources and to produce different outputs, according to the property required for investigation. In general, location of sedimentary particles accumulation indicates positions of pollution risk. The observation of such locations is especially important in periods of elevating temperature that favours the emergence of eutrophic events, as a combined effect of algal-growth favourable ambient conditions and elevated trophic levers due to particle enrichment with nutrients from extensive irrigation of the adjacent land area during dry seasons. The regions of inner Thermaikos and Thessaloniki bay are highly affected by these processes owing to high suspended masses observed and to the relatively low water depths. This application can be used for the prognosis of seawater quality, as part of a near real-time observational system, and to formulate decisions for the protection of the seawater environment from pollution incidents, after their detection from the monitoring stations in the Thermaikos Gulf, as part of a pollution incidents management system.

\section{Appendix A}

Table A1. Values of critical shear stress for erosion $\tau_{c r, e r}$ and erosion rate constant $\varepsilon_{M}$ from published in-situ and laboratory experiments.

\begin{tabular}{|c|c|c|c|}
\hline Author & Area & $\tau_{c r, e r}[\mathrm{~Pa}]$ & $\varepsilon_{M}\left[\mathrm{kgm}^{-2} \mathrm{~s}^{-1}\right]$ \\
\hline Amos et al. $(1992,1997)$ & $\begin{array}{l}\text { Shallow tidal area } \\
\text { Clay exposed to air }\end{array}$ & $0.11-0.5$ & $1-7.5 \times 10^{-4}$ \\
\hline Black (1997) & $\begin{array}{l}\text { Shallow tidal area } \\
\text { Benthic diatoms } \\
\text { After } \mathrm{H}_{2} \mathrm{SO}_{4} \text { treatment }\end{array}$ & $\begin{array}{l}0.13 \\
0.03\end{array}$ & $\begin{array}{l}1.1 \times 10^{-4} \\
7.8 \times 10^{-4}\end{array}$ \\
\hline Ganaoui et al. (2004) & $\begin{array}{l}\text { Deltaic area } \\
\text { Overlying fluff layer } \\
\mathrm{D}_{50}=15-50 \mu \mathrm{m}\end{array}$ & $\begin{array}{l}0.025-0.05 \\
0.2-0.22\end{array}$ & $\begin{array}{l}2-6 \times 10^{-6} \\
6-15 \times 10^{-5}\end{array}$ \\
\hline Gust and Morris (1989) & $\begin{array}{l}\text { Coastal area } \\
\text { Consolidated } \\
\text { Overlying fluff layer }\end{array}$ & $\begin{array}{l}0.21 \\
0.02-0.08\end{array}$ & $\begin{array}{l}- \\
-\end{array}$ \\
\hline Houwing (1999) & $\begin{array}{l}\text { Shallow tidal area } \\
4-35 \% \text { clay with sand }\end{array}$ & $0.1-0.18$ & $5 \times 10^{-5}-3 \times 10^{-3}$ \\
\hline Krishnappan and Marsalek (2002) & $\begin{array}{l}\text { Artificial lagoon } \\
\text { Laboratory flume }\end{array}$ & $0.09-0.12$ & - \\
\hline Maa et al. (1993) & $\begin{array}{l}\text { Coastal area } \\
\text { Sandy } \\
\text { Clayey }\end{array}$ & $\begin{array}{l}0.22 \\
0.10-0.19\end{array}$ & $\begin{array}{l}- \\
-\end{array}$ \\
\hline Maa et al. (1998) & $\begin{array}{l}\text { Inner portal area } \\
\text { Overlying fluff layer } \\
\text { Consolidated }\end{array}$ & $\begin{array}{l}0.05 \\
0.1\end{array}$ & $\begin{array}{l}- \\
-\end{array}$ \\
\hline Mitchener and Torfs (1996) & $\begin{array}{l}\text { Homogenous bed } \\
\text { Mixtures 0-60\% sand }\end{array}$ & $0.1-0.2$ & $2-6 \times 10^{-4}$ \\
\hline Schünemann and Kuhl (1993) & $\begin{array}{l}\text { Shallow tidal area } \\
\text { Clay exposed to air }\end{array}$ & $0.20-0.74$ & - \\
\hline Schweimet al. (1998) & $\begin{array}{l}\mathbf{D}_{50}=\mathbf{1 5} \mu \mathbf{m} \\
\text { Consolidation time 3-21d }\end{array}$ & $0.1-0.175$ & $1-5 \times 10^{-5}$ \\
\hline Tolhurst et al. (2000) & $\begin{array}{l}\text { Estuarine clayey area } \\
\text { Laboratory flume } \\
\text { In situ measurements } \\
\text { Shallow tidal area } \\
\text { Relaxation time } \sim 1 \mathrm{~h} \\
\text { Relaxation time } \sim 4 \mathrm{~h} \\
\text { Relaxation time } \sim 18 \mathrm{~h} \\
\text { Tidal basin } \\
\text { Laboratory measurements } \\
\text { Lab. meas., correction } \\
\text { In situ measurements } \\
\text { Core measurements }\end{array}$ & $\begin{array}{l}1.65-17.25 \\
0.11-0.58 \\
0.15-2.3 \\
0.2-2.0 \\
0.21-2.0 \\
\\
0.20-1.95 \\
0.20-1.50 \\
0.19-3.3 \\
0.19-0.93\end{array}$ & $\begin{array}{l}- \\
- \\
- \\
- \\
- \\
- \\
- \\
- \\
-\end{array}$ \\
\hline Watts et al. (2003) & $\begin{array}{l}\text { Shallow tidal area } \\
\text { In situ measurements }\end{array}$ & $1.5-6$ & - \\
\hline Widdows et al. (1998) & $\begin{array}{l}\text { Shallow tidal area } \\
\text { Clay exposed to air } \\
\text { With overlying water }\end{array}$ & $\begin{array}{l}0.70-0.50 \\
0.18\end{array}$ & $\begin{array}{l}6.2 \times 10^{-5} \\
1.9 \times 10^{-3}\end{array}$ \\
\hline
\end{tabular}


Acknowledgements. This work was partially funded by the MFSTEP (Mediterranean Forecasting System Towards Environmental Predictions) European Program (EVK3-CT-2002-00075). Special thanks to K. Tsiaras of the Hellenic Centre for Marine Research for providing the hydrodynamic and physical parameters data resulting from his implementation of POM in the North Aegean Sea model.

Edited by: J. A. Johnson

\section{References}

Amos, C. L., Daborn, G. R., and Christian, H. A.: In situ erosion measurements on fine-grained sediments from the Bay of Fundy, Mar. Geology, 108, 175-196, 1992.

Amos, C. L., Feeney, T., Sutherland, T. F., and Luternauer, J. L.: The stability of fine-grained sediments from the Fraser River Delta, Estuar. Coast. Shelf Sci., 45, 507-524, 1997.

Anagnostou, Ch., Kaberi, E., Karageorgis, A., Kontoyiannis, H., Krassakopoulou, E., Pagou, K., Pavlidou, A., and Stavrakakis, S.: Matter transfer in a land-basin shelf: NW Aegean area Mediterranean Sea, Proceedings of the International Workshop on Environmental Biochemistry, New Delhi, 347-368, 1998.

Barros A. P. and Baptista, A. M.: An Eulerian-Lagrangian Model for Sediment Transport in Estuaries, in: Estuarine and Coastal Modeling, edited by: Spaulding, M., ASCE, 102-112, 1990.

Black, K. S.: Microbiological factors contributing to erosion resistance in natural cohesive sediments, in: Cohesive Sediments, edited by: Burt, N., Parker, R., and Watts, J., John Wiley \& Sons Ltd, Chichester, 231-244, 1997.

Burd, A. and Jackson, G. A.: Prediction particle coagulation and sedimentation rates for a pulsed input, J. Geophys. Res., 102(C5), 10 545-10610, 1997.

Estournel, Cl.: Modelling the transport of particulate matter on the Gulf of Lion continental shelf, METRO-MED, Final Scientific Report, Vol. I, 2000.

Ganaoui, O. El, Schaaff, E., Boyer, P., Amielh, M., Anselmet, F., and Grenz, C.: The deposition and erosion of cohesive sediments determined by a multi-class model, Estuar. Coast. Shelf Sci., 60, 457-475, 2004.

Ganoulis, G. G.: Engineering risk analysis of water pollution, VCH Pubs, Weinheim, 1994.

Houwing, E.-J.: Determination of the Critical Erosion Threshold of Cohesive Sediments on Intertidal Mudflats along the Dutch Wadden Sea Coast, Estuar. Coast. Shelf Sci., 49, 545-555, 1999.

Karageorgis, A., Anagnostou, Ch., Georgopoulos, D., and Albouisson M.: Distribution of suspended particulate matter determined by in-situ observations and satellite images in the NW Aegean Sea (Greece), Geo-Marine Letters, 20, 93-100, 2000.

Karageorgis, A. P. and Anagnostou, Ch. L.: Particulate matter spatial-temporal distribution and associated surface sediment properties: Thermaikos Gulf and Sporades Basin, NW Aegean Sea, Cont. Shelf Res., 21, 2141-2153, 2001.

Karamanos, H. and Polyzonis, E.: Dynamics of matter transfer and biogeochemical cycles: their modelling in coastal systems of the Mediterranean Sea, METRO-MED, Second Annual Scientific Report, Vol. II, 1998.

Karamanos, H., Durrieu de Madron, X., Polyzonis, V., and Ludwig, W.: The adjacent area as fresh water and particulate matter contributor to the coastal zone of the Mediterranean Sea: Gulf of Lyons and Thermaikos Gulf, METRO-MED, Final Scientific Report, Vol. I, 2000.

Kontoyiannis, H. and Papadopoulos, V.: Hydrography and circulation of the Thermaikos plateau in February 1998, July 1997 and May 1997 and a simple comparison of geostrophic vs. ADCPmeasured flow fields in approaching the estimation of horizontal mass fluxes, METRO-MED, Second Annual Scientific Report, Vol. I, 1998

Korres, G. and Lascaratos, A.: A one-way nested eddy resolving model of the Aegean and Levantine basins: implementation and climatological runs, Ann. Geophys., 22, 205-220, 2003, http://www.ann-geophys.net/22/205/2003/.

Kourafalou, V. H., Barbopoulos, K. A., Tsiaras, K., and Staneva, J. V.: Numerical studies on shelf dynamics: North Aegean Sea and Northwestern Black Sea, International Conference on Oceanography of the Eastern Mediterranean and Black Sea, Ankara, Turkey, 2002.

Kourafalou, V. H. and Barbopoulos, K.: High resolution simulations on the North Aegean Sea seasonal circulation, Ann. Geophys., 22, 251-265, 2003, http://www.ann-geophys.net/22/251/2003/.

Kourafalou, V. H., Savvidis, Y. G., Krestenitis, Y. N., and Koutitas, Ch. G.: Modelling studies on the processes that influence matter transfer on the Gulf of Thermaikos (NW Aegean Sea), Cont. Shelf Res., 24, 203-222, 2004.

Kourafalou, V. H. and Tsiaras, K. P.: A nested circulation model for the North Aegean Sea, Ocean Sci., 3, 1-16, 2007 , http://www.ocean-sci.net/3/1/2007/.

Krestenitis, Y. N.: Mathematical Study of the three-dimensional coastal circulation by algebraic transformations, $\mathrm{PhD}$ thesis, AUTh, Thessaloniki, in Greek, 1987.

Krishnappan, B. G. and Marsalek, J.: Transport characteristics of fine sediments from an on-stream stormwater management pond, Urban Water, 4, 3-11, 2002.

Lykousis, V., Collins, M. B., and Ferentinos, G.: Modern sedimentation in the N.N. Aegean Sea, Mar. Geology, 43, 111-130, 1981.

Maa, J. P. Y., Wright, L. D., Lee, C. H., and Shannon, T. W.: VIMS Sea Carousel: A field instrument for studying sediment transport, Mar. Geology, 115, 271-287, 1993.

Maa, J. P., Sanford, L., and Halka, J. P.: Sediment resuspension characteristics in Baltimore Harbor, Maryland, Mar. Geology, 146, 137-145, 1998.

Mellor, G. L.: Introduction to Physical Oceanography, Princeton University, New Jersey, 1996.

Metha, A. J.: Hydraulic Behaviour of fine sediment, Coastal, Estuarial and harbour engineer's reference book, Abott \& Price, Chapman \& Hall (Pubs.), London, 577-585, 1993.

McLane, M.: Sedimentology, Oxford University Press, New York, 1995.

Mitchener, H. and Torfs, H.: Erosion of mud/sand mixtures, Coastal Engineering, 29, 1-25, 1996.

Moustaka, M.: Oceanography, a biological approach, Exin Pubs., Thessaloniki, in Greek, 1997.

O’ Brien, J. J. (Ed.): Advanced Physical Oceanographic Numerical Modelling, NATO ASI Series, 1986.

Olson, D., Kourafalou, V., Johns, W., Samuels, G., and Veneziani, M.: Aegean Surface Circulation from a Satellite-tracked Drifter Array, J. Phys. Oceanography, in press, 2007.

Papadopoulos, A., Katsafados, P., Kallos, G., and Nickovic, S.: The 
Weather Forecasting System for Poseidon - an overview, The Global Atmosphere and Ocean System, 8(2-3), 219-237, 2002.

Pohlmann, T. and Puls, W.: Currents and Transport in water, in: Circulation and Contaminant Fluxes in the North Sea, SpringerVerlag Science, Michigan, 555-605, 1994.

Poulos, S. E,, Chronis, G. Th., Collins, M. B., and Lykousis, V.: Thermaikos Gulf Coastal System, NW Aegean Sea: an overview of water/sediment fluxes in relation to air-land-ocean interactions and human activities, J. Marine Syst., 25, 47-76, 2000.

Rodean, H. C.: Stochastic lagrangian models of turbulent diffusion, Meteorological Monographs, American Meteorological Society, Massachusetts, 1996.

Rodi, W.: Turbulence models and their application in Hydraulics, IAHR, 1993.

Savvidis, Y., Koutitas, C., and Krestenitis, Y.: Development and application of a three dimensional cohesive sediment transport mathematical model, Journal of Marine Environmental Engineering, 6, 229-255, 2001

Schünemann, M. and Kühl, H.: Experimental investigations of the erosional behaviour of naturally formed mud from the Elbe Estuary and adjacent Wadden Sea, Germany, in: Nearshore and Estuarine Cohesive Sediment Transport, edited by: Mehta, A. J., Coastal and Estuarine Studies, 42, 314-330, 1993.

Schweim, C., Bouchard, J. P., Welzel, J., Spork, V., and Köngeter, J.: Sediment management during reservoir depletion - experimental investigations of mud siltation and resuspension, 7th International Symposium on River Sedimentation, Hong Kong, 1998.
Soukissian, T. H., Chronis, G. T, Nittis, K., and Diamanti, Ch.: Advancement of Operational Oceanography in Greece: The Case of the Poseidon System, The Global Atmosphere and Ocean System, 8, 119-133, 2002.

Tolhurst, T. J., Riethmüller, R., and Paterson, D. M.: In situ versus laboratory analysis of sediment stability from intertidal mudflats, Cont. Shelf Res., 20, 1317-1334, 2000.

Toorman, E. A., Bruens, A. W., Kranenburg, C., and Winterwerp, J. C.: Interaction of Suspended Cohesive Sediment and Turbulence, Proc. INTERCOH, 2000.

Wang, X. H. and Pinardi, N.: Modeling the dynamics of sediment transport and resuspension in the northern Adriatic Sea, J. Geophys. Res., 107(C12), 18-1-18-23, 2002.

Watts, C. W., Tolhurst, T. J., Black, K. S., and Whitmore, A. P. In situ measurements of erosion shear stress and geotechnical shear strength of the intertidal sediments of the experimental managed realignment scheme at Tollesbury, Essex, UK, Estuar. Coast. Shelf Sci., 58, 611-620, 2003.

Widdows, J., Brinsley, M. D., Bowley, N., and Barrett, C.: A Benthic Annular Flume for In Situ Measurement of Suspension Feeding/Biodeposition Rates and Erosion Potential of Intertidal Cohesive Sediments, Estuar. Coast. Shelf Sci., 46, 27-38, 1998.

Winterwerp, J. C.: A simple model for turbulence induced flocculation of cohesive sediment, J. Environ. Eng., 36(3), 309-326, 1998.

Winterwerp, J. C.: On the dynamics of high-concentrated mud suspensions, Judels Brinkman \& Ammerlaan, Delft, 1999. 